\title{
Role of Early Brief Psychological Interventions in Substance Use Disorders
}

\author{
Muhammad Siddique Kakar, Shehzad Rauf, Muhammad Waleed Iqbal, Azaan Qureshi, Saad Nabeel \\ $-----------------------------------------$
}

ABSTRACT

Objective: To assess the effects of early brief psychological interventions in patients of substance use disorders.

Study Design and Setting: This descriptive prospective study was conducted at main reception centre filter clinic/ Emergency Department of PNS Shifa hospital from $1^{\text {st }}$ July 2020 to $31^{\text {st }}$ March 2021.

Methodology: Total $\mathrm{n}=78$ patients were identified after a simple screening question regarding substance abuse which was how many times the patient had used an illegal drug in the last one year. An answer of more than 1 was considered as a positive response and further screening was done with Drug and Alcohol screening test (DAST). Patients who showed low scores on DAST were recommended for brief interventions which were given as weekly sessions for 6 weeks and reassessment was done at $3^{\text {rd }}$ month. The SPSS 20 package program was used for statistical analysis. The descriptive statistics were analyzed for all the variables evaluated in the study.

Results: This study revealed that that after 3 months of brief psychological interventions, $43(55.1 \%)$ patients remained abstinent from drugs. $18(23 \%)$ patients did not report for follow up. $9(11.5 \%)$ had reduced their use while $8(10.2 \%)$ were still using drugs regularly.

Conclusion: This study showed that brief psychological interventions at the level of filter clinics/Emergency departments can help patients of substance use seek early care who fear going to a psychiatric clinic.

Keyword: Brief Psychological interventions, Primary care, Substance use disorders.

How to cite this Article:

Kakar MS, Rauf S, Iqbal MW, Qureshi A, Nabeel S. Role of Early Brief Psychological Interventions in Substance Use Disorders .J Bahria Uni Med Dental Coll. 2022; 12(1):31-34 DOI: https://doi.org/10.51985/JBUMDC2021029

This is an Open Access article distributed under the terms of the Creative Commons Attribution Non Commercial License (http:// creativecommons/org/licences/by-nc/4.0) which permits unrestricted non commercial use, distribution and reproduction in any medium, provided the original work is properly cited.

\section{INTRODUCTION:}

Around the world, it has been seen that the global burden of disease due to illicit substance use is around $1.5 \%$ and in

Muhammad Siddique Kakar

I Consultant Psychiatrist, Department of Psychiatry,

I PNS Shifa Hospital, Karachi

I Email: mskakar80@hotmail.com

I Shehzad Rauf

I Consultant Psychiatrist, Department of Psychiatry,

I PNS Shifa Hospital, Karachi

Email: shahzad.drcol@hotmail.com

I Muhammad Waleed Iqbal

Resident Psychiatry, Department of Psychiatry,

PNS Shifa Hospital, Karachi

I Email: drwaleed.khan.86@gmail.com

I

Azaan Qureshi

General Physician, Department of Psychiatry,

Civil Hospital, Karachi

I Email: drazaanabdullah@gmail.com

I Saad Nabeel

I Clinical Psychologist, Department of Psychiatry,

I PNS Shifa Hospital, Karachi

I Email: Saadgondal46@gmail.com

I Received: 24-May-2021

I Accepted: 12-Dec-2021

L some countries this is high as $5 \%$. World wide data suggests that $5.5 \%$ of the world population aged 15-64, had used drugs in the year 2017. A detailed analysis shows that the number of people who use drugs has increased by 30 per cent since $2009 .^{1}$ The most commonly used drug around the world in 2017 was cannabis, with an estimated 188 million users. In 2017, Opiod overdose lead to the death of 47,000 people which is 13 per cent higher than the previous year, however around 100,000 deaths were reported due to overdose of opiod. The cumulative number of deaths which may be due to substance abuse including long term smoking, alcohol use and other illicit drug abuse was around 11.4 million deaths in 2017. By combining these deaths, it has been established that the leading risk factor for premature death globally is substance abuse. It is evident that the age of more than half Literature revealed that the prevalence of drug dependence in males is two times higher than females. In 2016, 2.4\% males and 1.2\% females were drug dependent. ${ }^{2}$

As per UNODC survey report of 2013, approximately 6.7 million people in Pakistan were involved in illicit substance use in 2012. Total disease burden due to psychoactive substance abuse in Pakistan was $1.18 \%$ whereas $2.39 \%$ of Pakistan population was involved in substance abuse. The death rate was 1.71 per 100000 in Pakistan. Cannabis was most commonly used drug in Pakistan and was prevalent in 
Role of Early Brief Psychological Interventions in Substance Use Disorders

$3.6 \%$ of the population which was roughly equivalent to about four million users nationwide. Every one in five drug addict was found to be involved in poly drug abuse. An estimated 860,000 or 0.8 per cent of the population were regular heroin users and 320,000 (0.3\%) were opium users. ${ }^{3}$

Studies have shown that identification of substance use disorders at primary care level can help patients overcome in handling substance abuse disorders and have severe time limitations due to the increased load of patients. ${ }^{4,5}$ Globally the availability of treatment for substance abuse remains less than its actual requirement with only one in seven people receiving treatment each year. The primary care clinician's give some sort of supportive treatment in the initial phase of the disorders. ${ }^{6}$ A study in 2017 showed that collaborative care involving brief behavioral interventions and psychotherapy at the primary care level helped the patient remain abstinent for a longer period of time as compared to regular care that is given to drug addicts ${ }^{7}$. The major hindrances for referring patients directly to psychiatric clinic are the scarcity of available facilities, the financial load and stigma associated with psychiatric treatment and the ambivalence of patients towards seeking long term addiction treatment. ${ }^{8}$ Another option already being implemented in Europe is to have clinical psychologists/therapists/ councilors offer psychological services on-site in coordination with the primary care systems which can help reduce stigma and increase patient access to appropriate treatment. ${ }^{9,} 10$

Hence, the rationale of this study was to look into the application of brief psychological interventions at an early level at primary care level in Pakistan to see their effect in the recovery of patients of substance abuse. Therefore this study was aimed to assess the effects of early brief psychological interventions in patients of substance use disorders.

\section{METHODOLOGY}

This was a descriptive prospective study conducted at main reception center/emergency department PNS Shifa Hospital from $1^{\text {st }}$ July 2020 to $31^{\text {st }}$ March 2021. The research was approved by the Ethical Committee of PNS Shifa hospital vide ERC no ERC/2020/Psy/25.The sample size calculated by WHO formula was found to be 78 with a confidence interval of $80 \%{ }^{7}$ These patients were identified after a simple screening question regarding substance abuse which was how many times the patient had used an illicit substance in the last one year. An answer of more than 1 was considered as a positive response for further screening. ${ }^{11}$

Sample collection was done through random sampling technique. The exclusion criteria included presence of any other psychiatric illness and lack of consent on part of the patient whereas inclusion criteria included the use of any illicit substance. Drug and Alcohol screening test (DAST) this disorder but the primary care physicians are less trained responsibility is increasing and they need to be trained to

was applied on all patients during the interview. If the patients showed a score of up to 2 on DAST, they were recommended for brief interventions by the clinical psychologist at the primary care clinic. If the patients showed score of 3 or more on DAST they were referred onwards to psychiatrists for detailed assessment and interventions including laboratory based drug screening tests. Brief interventions based on counseling, motivational interviewing and informational care was given over 6 sessions on a weekly basis by clinical psychologist and resident psychiatrists. Patients were called for follow up at the $3^{\text {rd }}$ month and the screening scales were reapplied. The SPSS 20 package program was used for statistical analysis. Variables were described as mean \pm SD. The descriptive statistics were analyzed for all the variables evaluated in the study.

\section{RESULTS}

A total of 78 male patients participated in the study. Participants mean age was 26.4 years $( \pm 9.6)$. Majority of the subjects had some level of education $(80.7 \%)$ whereas $21.7 \%$ of the patients were students. Total 34(43.5\%) patients were unemployed. Cannabis was the most abused substance $(48.7 \%)$ followed by Heroin $(17.9 \%) .14(17.9 \%)$ of the subjects were also involved in poly substance abuse.

Brief psychological interventions including motivational interviewing, informational care and drug abstinence based counseling was used over 6 weekly sessions and patients were reassessed after 3 months. It was seen that at the end of 3 months. That $43(55 \%)$ patients remained abstinent from drugs. Total 18(23\%) patients did not report for follow up, $9(11.5 \%)$ had reduced their use but still using it while $8(10.2 \%)$ were still using drugs regularly.

\section{Table 1: Demographic Distribution Of Patients}

\begin{tabular}{|l|c|c|}
\hline Age(Years ) & Frequency & Percentage (\%) \\
\hline$=25$ & 28 & 35.8 \\
\hline $26-36$ & 34 & 43.5 \\
\hline$>36$ & 16 & 20.5 \\
\hline Mean \pm SD & $26.4 \pm 9.6$ & \\
\hline Educational status & & \\
\hline Uneducated & 15 & 19.2 \\
\hline Matriculate & 24 & 30.7 \\
\hline Intermediate & 21 & 26.9 \\
\hline Higher studies & 18 & 23.0 \\
\hline Occupational status & & \\
\hline Employed & 27 & 34.6 \\
\hline Unemployed & 34 & 43.5 \\
\hline Students (college/university) & 17 & 21.7 \\
\hline Type of substance abuse & & \\
\hline Cannabis & 38 & 48.7 \\
\hline Heroine & 14 & 17.9 \\
\hline Amphetamines & 04 & 5.1 \\
\hline Alcohol & 08 & 10.2 \\
\hline Poly substance abuse & 14 & 17.9 \\
\hline
\end{tabular}


Muhammad Siddique Kakar, Shehzad Rauf, Muhammad Waleed Iqbal, Azaan Qureshi, Saad Nabeel

Table 2: Effect of Brief Interventions

\begin{tabular}{|l|c|r|}
\hline \multicolumn{3}{|c|}{ Effect of brief interventions (after 03 months) } \\
\hline Completely abstinent users & 43 & 55.1 \\
\hline Reduction of drug usage & 09 & 11.5 \\
\hline Failure to follow up & 18 & 23.0 \\
\hline Still using drugs regularly & 08 & 10.2 \\
\hline
\end{tabular}

\section{DISCUSSION:}

Research has shown long term substance use can lead to domestic violence and unemployment complicated by increased borrowing of money. It is suggested that peer groups, family behaviors and interactions can affect the behavior of substance abusers. ${ }^{12}$ Study comprising of 316 responses which were analyzed using regression analysis has shown that easy availability of illicit drugs, pressure of colleagues, avoidance of family and domestic conflicts have a significant effect on substance use. ${ }^{13}$ Another study from Pakistan based on a survey of 102 male candidates showed that a large number of the individuals $(35 \%)$ had initiated substance abuse in their teenage years. Majority of the respondents were skilled (60\%) and had secondary education (47\%), whereas $8 \%$ of the patients were students. The most commonly abused substance was heroine (48\%) followed by cannabis $(28 \%)$ whereas domestic disputes and peer pressure were the most common reasons for starting substance abuse. It was also seen that around $46 \%$ of patients suffered from co morbid depression. ${ }^{14}$ Research has recommended establishing addiction study centers at college and university level to counter the increased menace of substance abuse in students. ${ }^{15}$ Patients of substance use thrive on the basis of a strong therapeutic relationship with their doctors/councilors or "Recovery coaches" and are particularly sensitive about their confidentiality. In order to achieve both these targets, an improvement in primary care resources and substance use based training is needed to increase therapeutic relationship and doctor/ councilor's preparedness to address substance use. ${ }^{16}$ Another similar study has also shown that primary care intervention and adequate training of primary care physicians can help promote drug safety behavior. A comprehensive approach known as Screening, Brief Intervention, and Referral to Treatment (SBIRT) can help in the delivery of early intervention and treatment services by universally screening persons who have substance use disorders or are at risk of developing these disorders. Research has shown that application of SBIRT lead to short-term improvements in individuals, however the long-term effects on population health are yet to be seen. ${ }^{17}$ The American College of Physicians suggested integrating principles of SBIRT into primary care by utilizing existing primary care clinic-based psychologists to conduct the brief interventions and facilitate early referral to treatment. ${ }^{18,19}$. A study based on Alcohol, Smoking, Substance Involvement Screening Test (ASSIST) - a sensitive screening questionnaire to help identify misuse of alcohol and other substances - linked to Brief Intervention (BI) in which ASSIST questionnaire was used to screen patients attending primary care units and further categorize the patients into 'low-risk', 'moderaterisk' and 'high-risk' groups. Patients at 'moderate-risk' were given ASSIST-linked BI over a six-month trial. The percentages of patients who converted from moderate to 'low-risk' category were $36.7 \%$ at 3 months, and $53.3 \%$ at 6 months. ${ }^{20}$ In another trial, the participants with opiod and Alcohol use Disorders were treated with Brief interventions over 6 sessions group compared with usual care and it was found that brief interventions participants reported increased abstinence from opioids or alcohol at 6 months (32.8\% vs $22.3 \%$ ) respectively. ${ }^{7}$ A study involving 731 participants from four countries: Australia, Brazil, India and the United States who were given Brief Interventions based on their moderate ASSIST scores found that these interventions help reduced ASSIST scores to mild levels indicating effectiveness of Brief Interventions. ${ }^{21}$ Another research conducted on 780 participants who were given therapist based brief interventions showed that post interventions patients had a reduced intake or abstinence from all form of drugs including alcohol. ${ }^{22} \mathrm{~A}$ RCT conducted on 718 individuals comparing brief interventions including motivation interviewing and health informational care sessions found both of them effective at reducing frequency or abstinence of heavy drinking and stimulant use but had no effect on cannabis use. ${ }^{23}$ Anderson et al established that primary care training and support in alcohol screening and brief advice had an impactful effect on patients who received the intervention that was sustained even after 9 months. ${ }^{24}$ This study also showed that early and brief interventions at the level of filter clinics or emergency departments can be helpful in reducing substance use disorders.

However there are some limitations including the smaller sample size of the study, the shorter duration of follow ups and the high risk of patients failing to continue their review. Detailed research needs to be conducted in Pakistan regarding the process and funding of screening of all patients along with utilization, training and availability of clinical psychologists in Main Reception Centers of hospitals to help promote treatment of such disorders

\section{CONCLUSION}

Patients of substance use disorders who find it difficult to visit psychiatric clinics can be identified early by simple screening at emergency/filter clinics. Brief psychological interventions applied at the level of these clinics can help in abstinence and reduction of use of such substances.

- - - - - - - - - - - - - -

| Authors Contribution:

Muhammad Siddique Kakar: Main author, selection of topics \& synopsis

I Shehzad Rauf: Supervisor, Methodology

Muhammad Waleed Iqbal: Data Collection, brief interventions

Azaan Qureshi: Statistical analysis

| Saad Nabeel: Brief interventions, data collection

- - - - - - - - - - - - - - - - 
Role of Early Brief Psychological Interventions in Substance Use Disorders

\section{REFERENCES:}

1. Stanaway JD, Afshin A, Gakidou E, Lim SS, Abate D, Abate $\mathrm{KH}$ et al. Global, Regional, and National Comparative Risk Assessment of 84 Behavioural, Environmental and Occupational, and Metabolic Risks or Clusters of Risks for 195 Countries and Territories, 1990-2017?: A Systematic Analysis for the Global Burden of Disease Study 2017. The Lancet. 2018; 392 (10159): 1923-94. doi: http://dx.doi.org/ 10.1016/ S0140-6736(18)32225-6.

2. Roth GA, Abate D, Abate KH, Abay SM, Abbafati C, Abbasi $\mathrm{N}$ et al. Global, regional, and national age-sex-specific mortality for 282 causes of death in 195 countries and territories, 1980-2017: A systematic analysis for the Global Burden of Disease Study 2017. The Lancet. 2018; 392(10159), 17361788. doi: 10.1016/S0140-6736(18)32203-7

3. Unodc.org. 2021 [cited 26 October 2021]. Available from: https://www.unodc.org/documents/Pakistan/ Survey_Report_Final_2013.pdf

4. Shapiro B, Coffa D, McCance-Katz EF. A primary care approach to substance misuse. Am Fam Physician. 2013; 88(2):113-21.

5. McNeely J, Kumar P, Rieckmann T, Sedlander E, Farkas S, Chollak $\mathrm{C}$ et al. Barriers and facilitators affecting the implementation of substance use screening in primary care clinics: a qualitative study of patients, providers, and staff. Addiction Science \& Clinical Practice. 2018; 13(1). doi: 10.1186/s13722-018-0110-8

6. Center for Substance Abuse Treatment. A Guide to Substance Abuse Services for Primary Care Clinicians. Rockville (MD): Substance Abuse and Mental Health Services Administration (US); 1997. (Treatment Improvement Protocol (TIP) Series, No. 24.) Chapter 1 -Substance Abuse and Primary Care.[cited 26 October 2021] Available from: https://www.ncbi .nlm. nih.gov/books/NBK64831/

7. Watkins K, Ober A, Lamp K, Lind M, Setodji C, Osilla K et al. Collaborative Care for Opioid and Alcohol Use Disorders in Primary Care. The SUMMIT randomized clinical trial. JAMA Internal Medicine. 2017;177(10):1480. doi: 10.1001/jamainternmed.2017.3947

8. Saitz R, Horton N, Larson M, Winter M, Samet J. Primary medical care and reductions in addiction severity: a prospective cohort study. Addiction. 2005;100(1):70-78. doi: 10.1111/ j.1360-0443.2005.00916.x

9. Ernst D, Miller W, Rollnick S. Treating substance abuse in primary care: a demonstration project. International Journal of Integrated Care. 2007;7(4). doi:10.5334/ijic.213

10. Sockalingam S, Arena A, Serhal E, Mohri L, Alloo J, Crawford A. Building Provincial Mental Health Capacity in Primary Care: An Evaluation of a Project ECHO Mental Health Program. Academic Psychiatry.2017;42(4): 451-457. https:// doi.org/10.1007/s40596-017-0735-Z

11. Smith PC, Schmidt SM, Allensworth-Davies D, Saitz R. A single-question screening test for drug use in primary care. Arch Intern Med. 2010; 170(13):1155-1160. doi:10.1001/ archinternmed.2010.140

12. Tanweer H, Batool Z, Chudhary, MS, Mahmood S. The Social Impact of Substance Abuse on Males livelihood in Punjab, Pakistan. European Online Journal Of Natural And Social Sciences. 2019; 8(4): 777-783.
13. Sahar M, Riaz S, Khan S. Substance abuse among educated youth: challenges and problems faced by the families in Karachi, Pakistan. The spark.2020.5 (1).188-208

14. Ghazal P. Rising trend of substance abuse in Pakistan: a study of sociodemographic profiles of patients admitted to rehabilitation centers, Public Health. 2019.167:34-37 https://doi:10.1016/j.puhe.2018.10.020

15. Sajid MA, Tatlah IA, Butt IH. Causes of Drug Abuse Among University Students in Pakistan: Variation by Gender And Drug Type. Pakistan Social Sciences Review. 2020;4(1):459468. doi: $10.35484 /$ pssr.2020(4-i)36

16. Jack HE, Oller D, Kelly J, Magidson JF, Wakeman SE. Addressing substance use disorder in primary care: The role, integration, and impact of recovery coaches. Substance Abuse, 2018; 39(3): 307-314 doi: 10.1080/08897077.2017.1389802

17. Babor T, McRee B, Kassebaum P, Grimaldi P, Ahmed K, Bray J. Screening, Brief Intervention, and Referral to Treatment (SBIRT). Substance Abuse. 2007; 28(3), 7-30. https://doi: 10.1300/J465v28n03_03

18. Rahm A, Boggs J, Martin C, Price D, Beck A, Backer T, et al. Facilitators and Barriers to Implementing Screening, Brief Intervention, and Referral to Treatment (SBIRT) in Primary Care in Integrated Health Care Settings. Substance Abuse. 2015; 36(3), 281-288. doi: 10.1080/08897077.2014.951140.

19. Crowley R, Kirschner N. The Integration of Care for Mental Health, Substance Abuse, and Other Behavioral Health Conditions into Primary Care: Executive Summary of an American College of Physicians Position Paper. Annals of Internal Medicine. 2015; 163(4), 298. doi: 10.7326/M150510 .

20. Assanangkornchai S, Nima P, McNeil E, Edwards J. Comparative trial of the WHO ASSIST-linked brief intervention and simple advice for substance abuse in primary care. Asian Journal of Psychiatry. 2015;18:75-80. doi: 10.1016/j.ajp.2015.09.003.

21. Humeniuk R, Ali R, Babor T, Souza-Formigoni M, de Lacerda $\mathrm{R}$, Ling $\mathrm{W}$ et al. A randomized controlled trial of a brief intervention for illicit drugs linked to the Alcohol, Smoking and Substance Involvement Screening Test (ASSIST) in clients recruited from primary health-care settings in four countries. Addiction. 2012;107(5):957-966. doi: 10.1111/j. 1360-0443.2011.03740.x

22. Drislane L, Waller R, Martz M, Bonar E, Walton M, Chermack $S$ et al. Therapist and computer-based brief interventions for drug use within a randomized controlled trial: effects on parallel trajectories of alcohol use, cannabis use and anxiety symptoms. Addiction. 2019;115(1):158-169. doi: 10.1111 /add.14781

23. Karno M, Rawson R, Rogers B, Spear S, Grella C, Mooney L et al. Effect of screening, brief intervention and referral to treatment for unhealthy alcohol and other drug use in mental health treatment settings: a randomized controlled trial. Addiction. 2020; 116(1): 159-169. doi: 10.1111/add.15114

24. Anderson P, Coulton S, Kaner E, Bendtsen P, $\mathrm{K}^{3}$ oda K, Reynolds J et al. Delivery of Brief Interventions for Heavy Drinking in Primary Care: Outcomes of the ODHIN 5-Country Cluster Randomized Trial. The Annals of Family Medicine. 2017;15(4):335-40. Doi: 10.1370/afm.2051 